\title{
Phylogenetic analysis of Sicilian goats reveals a new mtDNA lineage
}

\author{
M. T. Sardina* , M. Ballester ${ }^{\dagger}$, J. Marmi ${ }^{\dagger}$, R. Finocchiaro*, J. B. C. H. M. van Kaam ${ }^{\ddagger}$, B. Portolano* \\ and J. M. Folch ${ }^{\dagger}$ \\ * Dipartimento S.En.Fi.Mi.Zo.-Sezione Produzioni Animali, Facoltà di Agraria, Università degli Studi di Palermo, Viale delle Scienze, Palermo \\ 90128, Italy. 'Departament de Ciència Animal i dels Aliments, Facultat de Veterinària, Universitat Autònoma de Barcelona, Bellaterra 08193, \\ Spain. ${ }^{\ddagger}$ Istituto Zooprofilattico Sperimentale della Sicilia 'A. Mirri', Via G. Marinuzzi 3, 90129 Palermo, Italy
}

\section{Summary}

\begin{abstract}
The mitochondrial hypervariable region 1 (HVR1) sequence of 67 goats belonging to the Girgentana, Maltese and Derivata di Siria breeds was partially sequenced in order to present the first phylogenetic characterization of Sicilian goat breeds. These sequences were compared with published sequences of Indian and Pakistani domestic goats and wild goats. Mitochondrial lineage A was observed in most of the Sicilian goats. However, three Girgentana haplotypes were highly divergent from the Capra hircus clade, indicating that a new mtDNA lineage in domestic goats was found.
\end{abstract}

Keywords goat, hypervariable region 1, mitochondrial DNA, Sicilian breeds.

Domestic goats (Capra hircus) are important and adaptable animals that humans have domesticated (Porter 1996). They provide a full range of useful products to humans including meat, milk, skin and hair. Archaeological studies showed that goats were probably first domesticated in the Fertile Crescent region around 10000 years ago (Zeder \& Hesse 2000). Mannen et al. (2001) have suggested that at least two wild species of the genus Capra have contributed to the gene pool of domestic goats, whereas a second independent domestication event may have given rise to the Cashmere-like goat breeds in Pakistan (Meadow 1993). However, most of the issues related to the origins of domestic goats still remain uncertain and controversial.

To elucidate the origin and genetic diversity of caprine breeds, recent studies based on mtDNA sequences (Luikart et al. 2001; Sultana et al. 2003; Joshi et al. 2004) have allowed the identification of several maternal lineages, suggesting that the goat was domesticated from different populations of the wild bezoar goat (Capra aegagrus). In domestic goats five maternal lineages (A-E) have been described based on mtDNA data. Luikart et al. (2001) partially sequenced the mtDNA hypervariable region 1 (HVR1) and defined mitochondrial lineages A, B and C. Mitochondrial lineage $\mathrm{A}$ is predominant and corresponds to the

Address for correspondence

Josep M. Folch, Departament de Ciència Animal i dels Aliments, Facultat de Veterinària, Universitat Autònoma de Barcelona, Bellaterra 08193, Spain.

E-mail: josepmaria.folch@uab.es

Accepted for publication 17 February 2006 initial domestication event. Mitochondrial lineages B (detected in India, Malaysia, Mongolia and Pakistan) and C (detected in Slovenia, Switzerland and Mongolia) represent recent secondary expansions. Most recently, Sultana et al. (2003) found mitochondrial lineage $C$ in Pakistan, and Joshi et al. (2004) detected mitochondrial lineages D and E in India. Chen et al. (2005) found the four mitochondrial lineages A, B, C and D in Chinese goat breeds.

There are several hypotheses about the origin of Sicilian goats. According to morphology, the Girgentana breed probably came from Afghanistan and the Himalaya regions (Portolano 1987). The origin of Maltese and Derivata di Siria goats remains uncertain. However, it has been suggested that the Maltese goat originated in Malta Island due to crosses among the typical Mediterranean common goat and some breeds from North Africa; the Derivata di Siria probably came from the Middle East (Porter 1996). In 1983, the Girgentana population consisted of 30000 (Associazione Nazionale della Pastorizia (ASSONAPA 1984), while 10 years later almost $98 \%$ of the initial population disappeared (Giaccone et al. 1994). The aim of this study was to genetically characterize Sicilian goat breeds using the mtDNA HVR 1 sequence. It should be noted that Maltese and Derivata di Siria goats were investigated previously using blood biochemical polymorphisms (Rasero et al. 1988).

Blood samples from 67 Sicilian goats were collected from the Agrigento (Girgentana $n=33$, Maltese $n=11$ and Derivata di Siria $n=9$ ) and Palermo (Girgentana $n=14$ ) provinces. DNA was isolated from blood samples using a phenol-chloroform extraction method.

A fragment of the mtDNA control region was amplified using primers CGCTCGCCTACACACAAATA and 
Table 1 Molecular diversity indices from $546 \mathrm{bp}$ of the mtDNA hypervariable region 1 sequence in the Girgentana, Maltese, and Derivata di Siria breeds, and across these three breeds (all Sicilian). Haplotype and nucleotide diversities include standard deviations.

\begin{tabular}{llllll}
\hline & $\begin{array}{l}\text { Sample } \\
\text { size } \\
\text { Breed }\end{array}$ & $\begin{array}{l}\text { No. } \\
\text { haplotypes }\end{array}$ & $\begin{array}{l}\text { Haplotype } \\
\text { diversity }(h)\end{array}$ & $\begin{array}{l}\text { No. } \\
\text { polymorphic } \\
\text { sites }\end{array}$ & $\begin{array}{l}\text { Nucleotide } \\
\text { diversity }(\pi)\end{array}$ \\
\hline Girgentana & 47 & 24 & $0.963 \pm 0.011$ & 78 & $0.02415 \pm 0.00530$ \\
Maltese & 11 & 6 & $0.855 \pm 0.085$ & 13 & $0.00917 \pm 0.00130$ \\
Derivata di Siria & 9 & 5 & $0.806 \pm 0.120$ & 19 & $0.01252 \pm 0.00237$ \\
All Sicilian & 67 & 33 & $0.969 \pm 0.007$ & 84 & $0.02359 \pm 0.00450$ \\
\hline
\end{tabular}

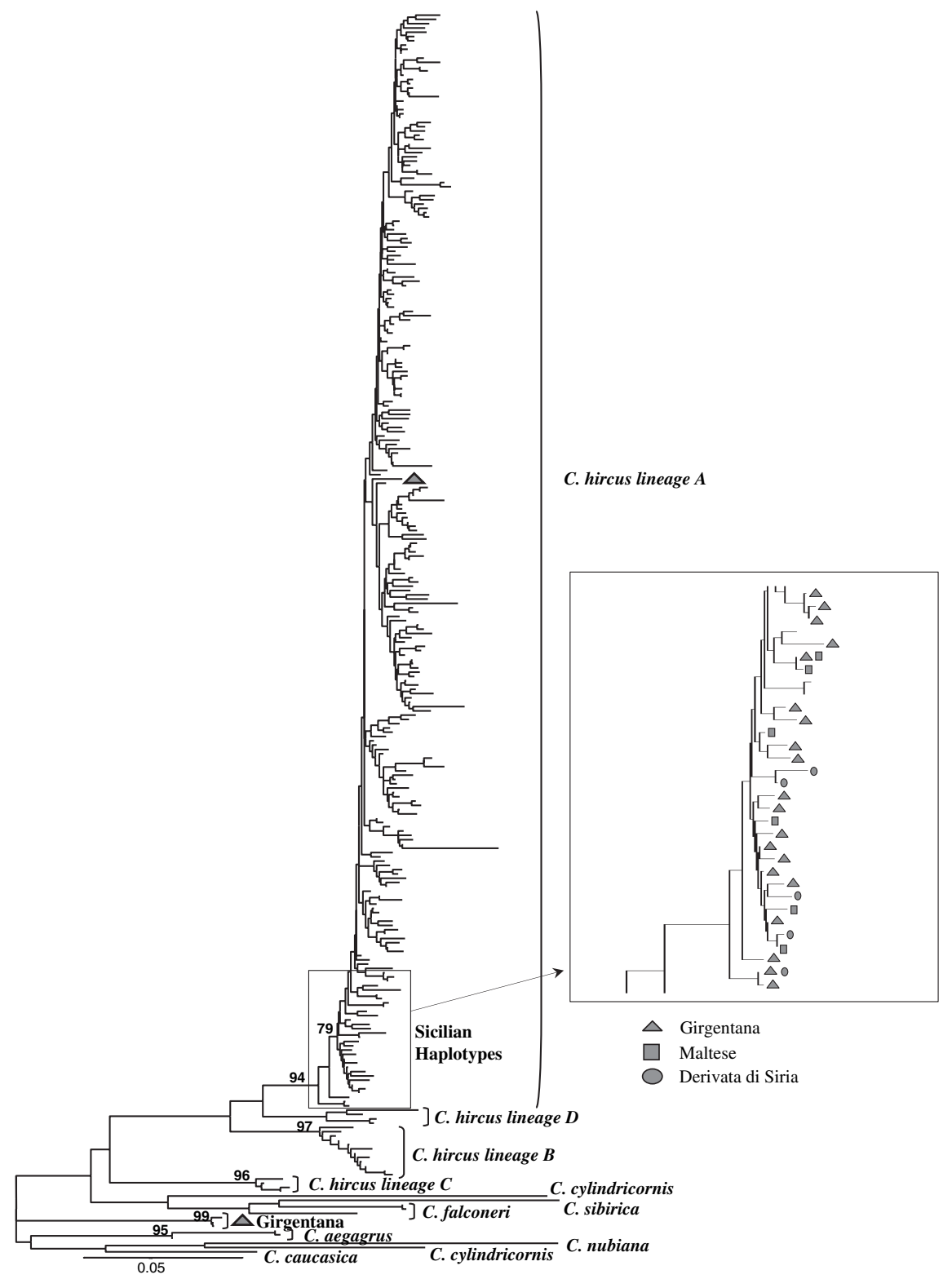

Figure 1 Neighbour-joining tree obtained considering haplotypes from Sicilian and wild goats, as well as sequences from GenBank.

AATGCCCATGCCTACCATTA (Amills et al. 2004), resulting in 546-bp fragment. Amplified products were sequenced in a 3730 DNA Analyser (Applied Biosystems, Foster City, CA, USA) according to the manufacturer's instructions.
Sequences (DQ241305-DQ241371) were aligned via Clustal W (Thompson et al. 1994) using BioEdit v7.0.5 (Hall 1999). Included in the analysis were 14 mtDNA HVR1 sequences from seven wild goat species 
(AB044305-AB044306, AJ317864-AJ317875), as well as sequences of domestic goats from Joshi et al. (2004) (AY155674, AY155875, AY155883 and AY156039) and from Sultana et al. (2003) (AB044295-AB044304, AB110552-AB110589). Positions 15 705-16 250 of all sequences were analysed. Using the DnaSP v4.10.3 software (Rozas et al. 2003), genetic diversity indices (number of haplotypes, haplotype diversity, number of polymorphic sites and nucleotide diversity) were determined for each breed as well as for the whole Sicilian population (Table 1). A neighbour-joining (NJ) tree was constructed with MEGA v3.0 (Kumar et al. 2004) using the Tamura-Nei model with $\alpha=0.29$ (according to Luikart et al. 2001) and 1000 bootstrap replications. Genetic distances between Sicilian breeds were computed with the same parameters.

Thirty-three haplotypes were obtained from the 67 HVR 1 sequences; these included five haplotypes typical for the Maltese breed and four haplotypes typical for the Derivata di Siria breed. Only two haplotypes were shared between breeds, one between the Girgentana and Maltese breeds and one between the Girgentana and Derivata di Siria breeds. The remaining 22 haplotypes were typical for the Girgentana breed. The Girgentana goat breed displayed the highest haplotype diversity $(0.963 \pm 0.011)$ and nucleotide diversity $(0.02415 \pm 0.00530)$. This haplotype diversity is in accordance with the previously described values in Indian and Chinese goats (Joshi et al. 2004; Chen et al. 2005 respectively), although the Girgentana breed suffered a drastic decrease in its population size during the 1980s. Genetic distances comparing Girgentana vs. Maltese and Derivata di Siria were $0.023 \pm 0.004$ and $0.026 \pm 0.004$ respectively. The lowest genetic distance was found between the Maltese and Derivata di Siria breeds (0.012 \pm 0.003$)$.

The NJ tree (Fig. 1) indicates that some Sicilian haplotypes were more closely related than with other populations, suggesting genetic isolation in Sicilian breeds. The mitochondrial lineage A was detected in all Sicilian haplotypes with the exception of three Girgentana haplotypes that were very different from previously described lineages. These three haplotypes clustered with wild goat haplotypes (Fig. 1). This result could be explained assuming a new mtDNA lineage or a historical introgression from wild goats. Further studies will be needed to investigate the origin of the Girgentana goat, one of the most autochthonous breeds in Sicily. In addition, the extinction of the Girgentana breed may result in the loss of important genotypes in domestic goats. This reinforces the need to promote a conservation program to avoid the extinction of Girgentana goat breed.

\section{Acknowledgements}

This research was conducted while the first author was supported by a grant of the University of Palermo. Dr J. B. C.
H. M. van Kaam had a Marie Curie European Reintegration Grant of the European Community programme 'Quality of Life' under contract number MERG-CT-2004-516458 during this research.

\section{References}

Amills M., Capote J., Tomàs A., Kelly L., Obexer-Ruff G., Angiolillo A. \& Sanchez A. (2004). Strong phylogeographic relationships among three goat breeds from the Canary Islands. Journal of Dairy Research 71, 257-62.

Associazione Nazionale della Pastorizia (ASSONAPA) (1984). Libro Genealogico Nazionale della Specie Caprina. Regolamenti, Roma, Italy.

Chen S.-Y., Su Y.-H., Wu S.-F., Sha T. \& Zang Y.-P. (2005). Mitochondrial diversity and phylogeographic structure of Chinese domestic goats. Molecular Phylogenetics and Evolution 37, 804-14.

Giaccone P., Portolano B., Bonanno A. \& Leto G. (1994). Aspetti quantitativi della produzione lattea ed analisi della variabilità ambientale in caprini di razza Girgentana. Tecnica Agricola 46, 3-18.

Hall T.A. (1999). BIOEDIT: a user-friendly biological sequence alignment editor and analysis program for Windows 95/98/NT. Nucleic Acids Symposium Series 41, 95-8.

Joshi M.B., Rout P.K., Mandal A.K., Tyler-Smith C., Singh L. \& Thangaraj K. (2004). Phylogeography and origin of Indian domestic goats. Molecular Biology and Evolution 21, 454-62.

Kumar S., Tamura K. \& Nei M. (2004). MEGA3: integrated software for molecular evolutionary genetics analysis and sequence alignment. Briefings in Bioinformatics 5, 150-63.

Luikart G., Gielly L., Excoffier L., Vigne J-D., Bouvet J. \& Taberlet P. (2001). Multiple maternal origins and weak phylogeographic structure in domestic goats. Proceedings of the National Academy of Sciences of the United States of America 98, 5927-32.

Mannen H., Nagata Y. \& Tsuji S. (2001). Mitochondrial DNA reveal that domestic goat (Capra hircus) are genetically affected by two subspecies of bezoar (Capra aegagrus). Biochemical Genetics 39, $145-54$.

Meadow R.H. (1993). Animal domestication in the Middle East: a revised view from the eastern margin. In: Harappan Civilization (Ed. by G.L. Possehl), pp. 295-320. Oxford and IBH, New Delhi.

Porter V. (1996). Goats of the World. Farming Press, Ipswich, UK.

Portolano N. (1987). Pecore e Capre Italiane, pp. 249-73. Edagricole, Bologna.

Rasero R., Di Stasio L., Facello C., Giaccone P., Berra G.P. (1988). Polimorfismo biochimico del sangue di capra. Atti SISVET Mantova, 29 Settembre - 1 Ottobre. 42, 1331-3.

Rozas J., Sánchez-DelBarrio J.C., Messeguer X. \& Rozas R. (2003). DnaSP, DNA polymorphism analyses by the coalescent and other methods. Bioinformatics 19, 2496-7.

Sultana S., Mannen H. \& Tsuji S. (2003). Mitochondrial DNA diversity of Pakistani goats. Animal Genetics 34, 417-21.

Thompson J.D., Higgins D.G. \& Gibson T.J. (1994). Clustal W: improving the sensitivity of progressive multiple sequences alignment through sequence weighting, position specific gap penalties and weight matrix choice. Nucleic Acids Research 22, 4673-80.

Zeder M. \& Hesse B. (2000). The initial domestication of goat (Capra hircus) in the Zagros Mountain 10,000 years ago. Science 287, 2254-7. 